\title{
REPRESENTAÇÕES DE MULHERES ATLETAS NO VOLEIBOL SENTADO BRASILEIRO
}

\author{
Vitória Crivellaro Sanchotene ${ }^{1}$ \\ Raquel Valente de Oliveira ${ }^{2}$ \\ Recebido em: 29/02/2020 \\ Aprovado em: 23/04/2020
}

\begin{abstract}
Resumo: O voleibol sentado caracteriza-se como um esporte paralímpico, praticado no Brasil desde o ano de 2002 por homens e mulheres que apresentam algum tipo de deficiência física. Com o intuito de dar voz às mulheres enquanto atletas com deficiência no contexto esportivo, bem como preservar a memória do esporte paralímpico brasileiro, a pesquisa objetiva delinear os percursos de atletas da seleção brasileira feminina de voleibol sentado que participaram de Jogos Paralímpicos nas edições de 2012, em Londres, e de 2016, no Rio de Janeiro. Para tanto, as informações foram coletadas por meio de entrevistas semiestruturadas, utilizando como pressupostos teóricos a História Cultural do Esporte e a Memória Esportiva. Evidenciamos que os percursos esportivos das cinco atletas investigadas incluem a rápida ascensão na carreira, possivelmente influenciados pela carente difusão da modalidade entre mulheres com deficiência física no Brasil na época em que ocorreram as suas inserções no esporte paralímpico. Na percepção das atletas, o ingresso no esporte de alto rendimento influenciou intensamente seus percursos de vida, modificando suas representações acerca da deficiência e do esporte.
\end{abstract}

Palavras-chave: voleibol sentado; mulheres; História do Esporte; esporte paralímpico; esporte para pessoa com deficiência.

Abstract: Sitting volleyball is characterized as a Paralympic sport, practiced in Brazil since 2002 by men and women who have some kind of physical disability. In order to give women a voice as athletes with disabilities in the sporting context, as well as to preserve the memory of Brazilian Paralympic sport, the research aims to outline the courses of athletes from the Brazilian women's volleyball team who participated in the 2012 Paralympic Games, in London, and 2016, in Rio de Janeiro. Therefore, the information was collected through semistructured interviews, using the Cultural History of Sport and Sports Memory as theoretical assumptions. We show that the sports trajectories of the five investigated athletes include the rapid rise in their careers, possibly influenced by the lack of diffusion of the sport among women with physical disabilities in Brazil at the time when their insertions in Paralympic

\footnotetext{
${ }^{1}$ Doutoranda do Programa de Pós-graduação em Ciências do Movimento Humano (PPGCMH), da Escola de Educação Física, Fisioterapia e Dança (ESEFID) da Universidade Federal do Rio Grande do Sul (UFRGS). Integrante do grupo de pesquisa Núcleo de Estudos em História do Esporte e da Educação Física (NEHME), do Observatório do Esporte Paralímpico e do Centro de Memória do Esporte (CEME). E-mail: vitoria.sanchotene@hotmail.com. ORCID iD: https://orcid.org/0000-0001-9731-5890.

2 Doutoranda do Programa de Pós-graduação em Ciências do Movimento Humano (PPGCMH), da Escola de Educação Física, Fisioterapia e Dança (ESEFID) da Universidade Federal do Rio Grande do Sul (UFRGS). Integrante do grupo de pesquisa Núcleo de Estudos em História do Esporte e da Educação Física (NEHME) e do Centro de Memória do Esporte (CEME). E-mail: raquelvvallente@hotmail.com. ORCID iD: https://orcid.org/0000-0003-1687-6456.
} 
sport occurred. In the athletes' perception, the entry into high-performance sport has intensely influenced their life paths, changing their representations about disability and sport.

Keywords: Sitting volleyball; women; Sport History; Paralympic sport; sport for people with disabilities.

Resumen: El voleibol sentado se caracteriza por ser un deporte paralímpico, practicado en Brasil desde 2002 por hombres y mujeres que tienen algún tipo de discapacidad física. Para dar a las mujeres una voz como atletas con discapacidades en el contexto deportivo, así como para preservar la memoria del deporte paralímpico brasileño, la investigación tiene como objetivo esbozar los cursos de atletas del equipo de voleibol femenino brasileño que participaron en los Juegos Paralímpicos de 2012, en Londres, y 2016, en Río de Janeiro. Por lo tanto, la información se recopiló a través de entrevistas semiestructuradas, utilizando la Historia Cultural del Deporte y la Memoria Deportiva como supuestos teóricos. Mostramos que las trayectorias deportivas de los cinco atletas investigados incluyen el rápido aumento en sus carreras, posiblemente influenciado por la falta de difusión del deporte entre las mujeres con discapacidades físicas en Brasil en el momento en que ocurrieron sus inserciones en el deporte paralímpico. En la percepción de los atletas, la entrada en el deporte de alto rendimiento ha influido intensamente en sus caminos de vida, cambiando sus representaciones sobre la discapacidad y el deporte.

Palabras clave: voleibol sentado; mujeres; Historia del deporte; Deporte paralímpico; deporte para personas con discapacidad.

\section{Introdução}

O voleibol sentado caracteriza-se como um esporte paralímpico ${ }^{3}$, praticado no Brasil desde 2002 por homens e mulheres que apresentam algum tipo de deficiência física. De acordo com Carvalho, Gorla e Araújo (2013), o ano de 2002 é o marco inicial da prática do voleibol sentado no Brasil, quando o professor Ronaldo Gonçalves de Oliveira organizou um torneio oficial na cidade de Mogi das Cruzes, no estado de São Paulo. No ano seguinte, em 2003, houve a fundação da Associação Brasileira de Voleibol Paraolímpico (ABVP), bem como a estruturação das primeiras seleções brasileiras de voleibol sentado, a masculina e a feminina.

Nesse mesmo ano, ambas as seleções competiram nos Jogos Parapan-Americanos, em Mar Del Plata, na Argentina. A partir de então, vieram a conquistar resultados positivos em muitas de suas participações em outros eventos esportivos (CARVALHO; GORLA; ARAÚJO, 2013). Tais competições foram importantes para que quase uma década após a introdução da prática do voleibol sentado no Brasil, se efetivasse a participação das seleções brasileiras de voleibol sentado, masculina e feminina, em Jogos Paralímpicos.

\footnotetext{
${ }^{3}$ Nesta pesquisa, utilizamos o termo "paralímpico" em conformidade ao adotado pelo Comitê Paralímpico Brasileiro (CPB), o qual atende a proposta do International Paralympic Committee (IPC).
} 
A primeira participação brasileira nas competições de voleibol sentado em Jogos Paralímpicos ocorreu quase 30 anos depois que a modalidade passou a integrar o rol dos esportes paralímpicos. A seleção brasileira masculina participou dos Jogos Paralímpicos de 2008, em Pequim (China), onde conquistou o sexto lugar na competição. A participação da primeira seleção brasileira feminina de voleibol sentado ocorreu somente na edição seguinte, nos Jogos Paralímpicos de 2012, em Londres (Inglaterra), após ter conquistado a vaga para participar do evento devido ao resultado obtido nos Jogos Parapan-Americanos de 2011, em Guadalajara (México).

Nos Jogos Paralímpicos de 2012, a seleção brasileira feminina de voleibol sentado terminou a competição em quinto lugar dentre oito países. Porém, na edição seguinte, nos Jogos Paralímpicos Rio 2016, ganhou destaque no cenário do esporte paralímpico internacional, conquistando o terceiro lugar na competição disputada entre oito países. Ao obter a medalha de bronze logo na segunda participação em Jogos Paralímpicos, as atletas da seleção brasileira feminina de voleibol sentado conquistaram certa visibilidade perante o cenário esportivo.

No que tange ao esporte paralímpico, esse é a forma institucionalizada de manifestação do esporte de alto rendimento para pessoas com deficiência. É considerada pessoa com deficiência "aquela que tem impedimento de longo prazo de natureza física, mental, intelectual ou sensorial” (BRASIL, 2011). Para Sanchotene e Mazo (2018, p. 573), “a prática do esporte adaptado e paralímpico atuam como meio de socialização e conscientização de todos os alunos e indivíduos, não apenas daqueles que tem deficiência”, podendo ser mais alastrado e desenvolvido em escolas, universidades, clubes e associações.

Com base neste panorama, a referida pesquisa tem como objetivo delinear os percursos de atletas da seleção brasileira feminina de voleibol sentado ${ }^{4}$ que participaram de Jogos Paralímpicos nas edições de 2012, em Londres, e de 2016, no Rio de Janeiro. De acordo com a análise da literatura realizada acerca da prática esportiva do voleibol sentado, há uma escassez de estudos nessa área acerca de seu alto rendimento no Brasil. Sanchotene e Mazo (2018) concluíram que, na literatura nacional, existem mais estudos voltados à inclusão social em escolas quando se trata de voleibol sentado, do que à vertente do alto rendimento desta modalidade paralímpica. Indo ao encontro disso, Sanchotene, Haiachi e Mazo (2018) afirmam que, embora o voleibol sentado esteja dentre os esportes paralímpicos mais pesquisados cientificamente, ainda há poucas investigações sobre as mulheres atletas.

\footnotetext{
${ }^{4}$ Cabe ressaltar que a seleção brasileira feminina de voleibol sentado é a seleção nacional adulta profissional, a qual é organizada e gerenciada pela Confederação Brasileira de Voleibol para Deficientes (CBVD).
} 
Dessa forma, optamos por dar voz às atletas mulheres como forma de enfatizar a temática da mulher enquanto atleta com deficiência no contexto esportivo, dando visibilidade ao tema e a essas protagonistas. Por meio deste estudo, pretendemos contribuir para a diminuição das lacunas supracitadas, ao preservar a memória do esporte paralímpico brasileiro, principalmente, por meio da produção de fontes orais sobre as mulheres atletas da seleção brasileira feminina do voleibol sentado. Também, esperamos asseverar a importância do voleibol sentado no processo de empoderamento de mulheres com deficiência em um país que, durante quase 40 anos, circunscreveu a prática de esportes convencionais às mulheres. Tal imposição legal teve suas ressonâncias de forma mais contundente no acesso a prática esportiva pelas mulheres com deficiência.

Para alcançar o objetivo proposta, utilizamos como pressupostos teóricos a História Cultural, recorrendo a autores como Burke (2005), Chartier (1988) e Pesavento (2003, 2004), bem como, para abordar a memória no âmbito do esporte, utilizamos os escritos de Ferreira (2002), Le Goff (1990) e Lopez (2008). Visto que, no Brasil, o voleibol sentado emergiu nos primeiros anos do século XXI, consideramos importante complementar a pesquisa sob a ótica da História Cultural, buscando compreender um fenômeno do mundo contemporâneo e trazendo as versões das atletas da seleção brasileira de voleibol sentado sobre seus percursos na prática esportiva paralímpica.

De acordo com Chartier (1988), a história singulariza-se pelo fato de manter uma relação com a verdade por meio de relatos, pretendendo reconstituir e tornar compreensível um passado. Essa reconstituição se faz por meio de "indícios, isto é, da realidade reconhecida a partir de seus vestígios” (CHARTIER, 1988, p. 85). Todo discurso histórico que se embasa nessa perspectiva da História Cultural se funda na constituição de representações - a partir de vestígios diversos - e nas relações entre as representações estabelecidas e as práticas culturais.

Neste estudo abrangemos as práticas do esporte, ou seja, uma prática esportiva que é a da modalidade paralímpica do voleibol sentado. Desta forma, as práticas esportivas geram representações para os personagens que constituem a seleção brasileira feminina de voleibol sentado. De acordo com Barros (2011), essas representações geram práticas, como atitudes e gestos e assim sucessivamente, sem conseguirmos perceber onde há o início e o fim do engendramento dessas noções.

Já no que diz respeito à memória, essa expressa uma relação estreita com os conceitos de história descritos acima. A história são os fatos ocorridos, enquanto a memória são as recordações e lembranças dos indivíduos que vivenciaram os fatos e que expõe suas opiniões de acordo com seus sentimentos e emoções. Esses dois conceitos são importantes para o 
embasamento desta investigação, a qual visa apreciar e reconhecer os depoimentos e reflexões acerca do voleibol sentado feminino no Brasil.

\section{Caminhos metodológicos}

Esta pesquisa caracteriza-se como qualitativa, com viés histórico-cultural. Ao fazer pesquisa qualitativa, o pesquisador busca "encontrar os significados das experiências pessoais que transformam as pessoas" (STAKE, 2011, p. 48). Esse tipo de pesquisa é uma interpretação de quem investiga um objeto de estudo, neste caso, a investigação se dará acreditando que não há tipicidade de uma época e nem generalizações a serem feitas em relação a grupos ou indivíduos. A realização deste estudo se alicerçou numa perspectiva do campo da História do Esporte, mais especificadamente na História do Esporte Paralímpico no Brasil. Vamplew (2013, p. 6) salienta que a história "pode registrar uma recordação esportiva" e, de tal modo, as memórias sobre o passado esportivo auxiliam a escrever essas histórias.

Tendo foco nas experiências pessoais das atletas da seleção brasileira feminina de voleibol sentado, coletamos, presencialmente ${ }^{5}$, por meio da técnica de entrevistas semiestruturadas, testemunhos sobre as memórias referentes aos percursos na seleção. Boni e Quaresma (2005) esclarecem que as entrevistas semiestruturadas utilizam perguntas abertas, por meio das quais o informante tem a possibilidade de discorrer sobre o tema proposto. A entrevista é uma forma de produzir fontes orais, as quais são compreendidas por serem "fontes voluntárias", pois existe uma intencionalidade em forma de depoimento do entrevistado ao responder as perguntas que são feitas pelo entrevistador (BARROS, 2012).

O critério de inclusão das atletas foi a participação nas edições dos Jogos Paralímpicos de Londres em 2012 e/ou nos Jogos Paralímpicos do Rio de Janeiro em 2016. A partir do critério estabelecido, bem como da disponibilidade/interesse em participar do estudo, cinco atletas integraram a pesquisa ${ }^{6}$ a saber: Ádria Jesus da Silva; Gizele Maria da Costa Dias; Jani Freitas Batista; Paula Angeloti Herts; e Suellen Cristina Dellangelica Lima. Cabe ressaltar que as atletas assinaram o Termo de Consentimento Livre e Esclarecido (TCLE), respeitando os

\footnotetext{
${ }^{5}$ As entrevistas com as atletas Ádria, Jani, Paula e Suellen foram realizadas na cidade de Goiânia/Goiás, durante a segunda etapa do Campeonato Brasileiro de Voleibol Sentado, entre os dias 19 e 21 de outubro de 2018. Já a entrevista com a quinta atleta, Gizele, foi realizada em São Paulo/SP, durante o curso de voleibol sentado do PréCongresso Paradesportivo Internacional no Centro de Treinamento Paraolímpico Brasileiro, no dia 30 de outubro de 2018.

${ }^{6}$ As cinco atletas que integraram o estudo autorizaram a divulgação de seus nomes e respostas. Para dar voz a elas e valorizar seus percursos esportivos, optamos por manter, ao longo do texto, os nomes verdadeiros das participantes, juntamente com suas respectivas respostas.
} 
procedimentos éticos descritos na dissertação de mestrado de Sanchotene (2019), aprovado pelo Comitê de Ética em Pesquisa (CEP) da Universidade Federal do Rio Grande do Sul (UFRGS), sob o protocolo número 27.331.

A análise qualitativa do conteúdo das entrevistas se embasou no processo recomendado por Flick (2009), visando a elaboração das categorias de análise temática. A partir desta orientação, buscamos analisar e descrever trechos obtidos por meio de entrevistas. Identificar os termos mais utilizados nas narrativas contribuiu para a categorização. Ademais, realizamos o cruzamento das informações coletadas com a literatura já produzida sobre o assunto. $\mathrm{O}$ confronto dos dados obtidos permitiu organizar as respostas conforme a categoria de interesse deste estudo - o percurso esportivo das atletas da seleção brasileira feminina de voleibol sentado.

\section{Percursos de mulheres no voleibol sentado}

Os Jogos Paralímpicos é o maior evento de esporte paralímpico no mundo. Existem diferentes vertentes de esporte para pessoas com deficiência, como lazer, escolar, reabilitação, assim como o alto rendimento, institucionalizado, com regras estipuladas e sistema de classificação, o chamado esporte paralímpico. Reis, Mezzadri e Silva (2017) salientam que o esporte paralímpico se caracteriza por fazer parte de um grupo restrito de esportes e modalidades que se enquadram nos Jogos Paralímpicos, em que os esportistas precisam passar por um processo de classificação para que possam ingressar em tais eventos esportivos. Dentre as modalidades disputadas nos Jogos Paralímpicos, encontra-se o voleibol sentado, que se apresenta como uma alternativa esportiva para as pessoas com deficiência física.

Com base no objetivo proposto acerca dos percursos das atletas da seleção brasileira feminina de voleibol sentado, serão apresentados e discutidos os resultados obtidos a partir das informações coletadas, considerando a revisão bibliográfica realizada e o referencial teórico adotado na pesquisa. Constatamos que o percurso esportivo das cinco atletas na prática do voleibol sentado perpassou diferentes momentos, circunscrevendo histórias que por vezes possuem similaridades e, em outras, marcam particularidades de seus percursos, evidenciando amplas influências dos contextos social e cultural de cada entrevistada.

Deste modo, Jani coloca que na modalidade do voleibol sentado ainda há pouco "material humano" e que, por esse motivo, as atletas que se destacam nos campeonatos brasileiros são convocadas para compor a seleção brasileira feminina de voleibol sentado. É possível perceber o rápido processo de Jani na introdução da seleção brasileira, uma vez que 
ela sofreu o acidente e passou pelo processo de protetização no ano de 2006 e, em 2008, já estava compondo a equipe que representava o Brasil nas competições nacionais da modalidade naquele ano. Como relata:

Então, com um campeonato desse brasileiro, que eles vão olhar as melhorzinhas de cada equipe para juntar a seleção brasileira. Ué, então eu sabia um pouquinho, tinha potencial e infelizmente falta material humano, então uma que aparece já é sugada pra seleção brasileira (JANI, 2018, p. 3).

Nesta passagem de sua fala, a atleta expõe que por haver poucas pessoas que praticam a modalidade no naipe feminino no Brasil, quando uma atleta compete no campeonato brasileiro de clubes, a comissão técnica da seleção brasileira entra em contato, principalmente, quando se destaca nos jogos. De acordo com Dantas (2018), o ano de 2006 foi um marco histórico para o voleibol sentado no Brasil, cuja modalidade teve seu primeiro campeonato nacional e, também, ocorreu a fundação da equipe feminina de voleibol sentado de Suzano (São Paulo), atual SESI-SP.

Jani foi treinar na Associação dos Deficientes Físicos do Estado de Goiás (ADFEGO), onde conheceu o voleibol sentado e o treinador Guedes, no ano de 2007. No ano seguinte, começou a treinar e a viajar. Antes dos Jogos Paralímpicos de 2012, Jani mudou de clube, onde ficou com sua colega Ádria treinando em Goiânia, com bolas e rede doadas pelo treinador Guedes. Hoje, treina na Associação dos Deficientes de Aparecida de Goiânia (ADAP), em Goiânia.

Atualmente, a atleta precisa conciliar o trabalho com o esporte. No início da carreira, como estava recebendo auxílio-acidente, ficou somente praticando o voleibol sentado. Para Jani, a maior dificuldade que encontrou em sua trajetória foi conciliar o esporte com o trabalho. Conta que ficou dois anos "sem ganhar nenhum centavo" (JANI, 2018, p. 4). Também, relata que não há muitas empresas que compreendem os tempos que as atletas passam viajando.

Jani menciona que jogou o campeonato Mundial em 2010 e os Jogos Paralímpicos. Em seu relato, expõe que em Londres, 2012, a seleção brasileira feminina de voleibol sentado ficou em $5^{\circ}$ lugar. No Mundial da China, cidade de Anji, no ano de 2015, ficou em $3^{\circ}$ lugar. Já em 2016, no Rio de Janeiro, ficou em $3^{\circ}$ lugar. Em suas memórias explanadas na entrevista, diz que nos Jogos Paralímpicos de Londres se achava imatura para saber da importância de jogos daquele nível (megaevento), porque se tornou atleta depois dos 20 anos. Atualmente, é capitã da ADAP de Goiânia e continua compondo a seleção brasileira de voleibol sentado. Conta que a família nunca assiste as competições e justifica que isso ocorre, pois, em sua família, não há outros atletas, fazendo com que desconheça a relevância disto. 
A segunda atleta entrevistada, Ádria, comenta que inicialmente tinha receio de participar da modalidade do voleibol sentado, no final do ano de 2005. Já em 2006, foi convocada para uma seletiva da seleção brasileira feminina de voleibol sentado, apesar de não ter sido convocada para a equipe que seguiria em treinamento. Essa explanação corrobora com o relato da atleta Jani, a qual também vivenciou uma rápida convocação para a seleção após sua iniciação na prática da modalidade. A partir disso, Ádria, sob comando do treinador Guedes, treinou mais um ano para que não houvesse novamente o corte da seleção. Indo ao encontro dessas memórias, Cardoso (2016) destaca a importância do papel do treinador para a continuação dos atletas paralímpicos em treinamento:

Esse suporte auxilia no aprimoramento dos resultados durante a carreira esportiva dos atletas. A contínua passagem de conhecimento durante os períodos de treinamentos e competições são fundamentais para que o atleta continue motivado a permanecer na modalidade esportiva paraolímpica ( $\mathrm{p}$. 99).

Em maio de 2006, Ádria ganhou o destaque de melhor bloqueadora da competição brasileira de voleibol sentado e foi convocada para compor a equipe das atletas da seleção brasileira daquele ano. No mês seguinte, em junho de 2006, a seleção viajou a Holanda para um Campeonato Mundial de Voleibol Sentado. Mesmo com o rápido avanço de Ádria em relação a seleção brasileira, ela conta que foi difícil aprender os fundamentos, principalmente o saque, mas a vontade de melhorar foi crescendo, conforme menciona: "eles investiram, apostaram e eu continuei. Vontade de desistir tive várias vezes, não vou mentir. Às vezes, eu desmotivava, mas voltava a treinar, treinar, treinava" (ÁDRIA, 2018, p. 2).

Viana, Chaves e Pereira (2015) mostram em seu estudo que as oportunidades de pessoas com deficiência em participarem de competições são fatores que contribuem para a permanência delas na prática esportiva, bem como estreita os vínculos com as outras pessoas que compõem o contexto esportivo. Os autores também evidenciaram que a melhora da saúde foi a questão menos apontada como motivo para inserção e constância na modalidade do voleibol sentado.

Assim como nos percursos de Jani e de Ádria, Paula também teve rápida convocação para a seleção brasileira de voleibol sentado, como expõe: "Comecei a treinar no início de 2011 e depois de um mês já tinha campeonato em Barueri. Depois dos jogos o técnico da seleção brasileira me convidou para fazer parte da equipe, e estou até hoje" (PAULA, 2018, p. 1). A atleta, ao lembrar-se de suas memórias com o voleibol sentado, se emocionou inúmeras vezes. Ao longo da entrevista, respirava fundo para não chorar e parecia, recorrentemente, que estava conseguindo visualizar como eram os momentos enquanto respondia com orgulho 
sobre a sua trajetória. Paula, ao falar sobre sua convocação à seleção brasileira, aludiu: “A emoção foi grande, pois sempre sonhei em defender o meu país e, de repente, você vê que está fazendo isso. De alguma forma eu me sinto feliz por ter representado meu país em algum momento na vida" (PAULA, 2018, p. 1).

Em conformidade com os depoimentos supracitados, Muñoz Galíndez e Montes Mora (2017, p. 5), ao entrevistar pessoas praticantes de voleibol sentado na Colômbia, sinalizam que "as histórias mostram que o voleibol sentado, mais do que um esporte onde há demanda física, é um espaço que permite a catarse e a liberdade do peso emocional que vem com a perda de um braço ou uma perna”. Essas histórias também são explanadas pelas atletas que compõem a seleção brasileira de voleibol sentado. Ádria conta que as melhores conquistas vieram a partir do ano de 2015, com os Jogos Parapan-Americanos de Toronto, onde conquistaram a medalha de prata. Ainda em 2015, houve a competição mundial, na China, que, segundo a atleta, foi o melhor campeonato que a seleção brasileira participou. Ádria, que mora com a mãe de 83 anos, diz que recebe apoio da sua família, a qual se orgulha de sua carreira.

Em seu relato, Gizele diz que era praticante de voleibol convencional desde os nove anos de idade, em que, apesar de ser voleibol amador, participava de campeonatos regionais. Um amigo, percebendo sua depressão pós-trauma, indicou-lhe a prática do voleibol sentado e apresentou-lhe ao técnico Ronaldo do SESI em 2009. A partir de então, Gizele começou a treinar em Jacareí (São Paulo) e no SESI. No ano seguinte, em 2010, foi chamada para a seleção brasileira, fato este que corrobora com a concepção de que há convocações da seleção brasileira feminina de voleibol sentado com as atletas que se destacam nos Campeonatos Brasileiros de Voleibol Sentado ou nos treinamentos, por haver pouco "material humano" (JANI, 2018, p. 3).

Gizele conta que competiu nos Jogos Parapan-Americanos de 2011. Narra que com a seleção brasileira teve a oportunidade de jogar em Dubai, na Ucrânia, no Egito, entre outros lugares. Além disso, jogou Jogos Parapan-Americanos de Toronto, o Intercontinental na Holanda e foi considerada a melhor atleta em sua função (levantadora) nos Jogos Paralímpicos do Rio de Janeiro do ano de 2016. A mesma relata:

Então, eu sou muito feliz, sou muito orgulhosa das coisas que eu faço, sou muito orgulhosa de dizer aquilo que eu faço, apesar de não ser reconhecida, mas eu gosto de dizer, do orgulho que eu tenho de ser o que eu sou hoje. Tudo o que eu conquistei na minha vida foi por causa do vôlei sentado. Minha casa comprei por causa do vôlei (GIZELE, 2018, p. 9). 
Indo ao encontro do relato de Gizele, Haiachi (2017, p. 219) identificou, em sua pesquisa com atletas com deficiência, que "a deficiência e o esporte foram considerados eventos marcantes no curso de suas vidas". De tal modo, é possível perceber que as atletas da seleção brasileira de voleibol sentado passaram por ressignificações em suas vidas, sendo, esta modalidade, a porta de entrada para a carreira esportiva paraolímpica, lugar ocupado por poucas. Isto porque, apesar da carência de recursos humanos, conforme depoimentos das entrevistadas, somente as pessoas que apresentam desempenho diferenciado têm a chance de integrar a seleção brasileira e participar das principais competições do esporte paralímpico, como os Jogos Parapan-Americanos e os Jogos Paralímpicos, por exemplo. Na percepção das cinco atletas entrevistadas, o ingresso no esporte de alto rendimento influenciou intensamente seus percursos de vida, modificando suas representações acerca da deficiência e do esporte. Por exemplo, Ádria, que relatou não gostar das aulas de Educação Física na escola, tampouco ter qualquer contato com esportes, declarou ter se apaixonado pelo voleibol sentado na perspectiva do alto rendimento profissional.

Sobre sua trajetória no voleibol sentado, Paula expõe que esteve em Pequim, na China, ganhando a medalha de bronze, foi medalha de prata em Toronto, no Canadá, e estava na seleção na conquista do bronze no Rio de Janeiro em 2016. Porém, treina no Clube dos Paraplégicos de São Paulo com a equipe masculina, uma vez que a equipe feminina teve suas atividades descontinuadas. Já Suellen apresenta que até se formar no ensino médio, continuou praticando o voleibol sentado paralelamente ao voleibol convencional, por ser classificada como mínima deficiência. Destacamos que Gizele e Suellen relatam ter jogado voleibol convencional antes de iniciar na prática do voleibol sentado.

No ano de 2008, Suellen passou a treinar exclusivamente no Clube Suzano, jogando somente o voleibol sentado. A mesma está na seleção de voleibol sentado desde o ano de 2006 e é a atual capitã da equipe. A atleta explica que durante sua trajetória foi classificada e reclassificada inúmeras vezes, por vezes se frustrando com o resultado e, em outras situações, com alegria perante sua classificação funcional. Por ter deficiência física na mão, a atleta teve que se adaptar ao longo dos anos com as mudanças das classificações no voleibol sentado. Suellen recorda ainda que, no ano de 2010, viajou com a equipe da seleção brasileira e foi classificada como mínima deficiência, porém, outras duas atletas também receberam esta classificação. Assim sendo, Suellen memora:

Então, eu sabia que para chegar nesse nível (da jogadora que substituiria na seleção brasileira), para eu jogar como titular, eu precisaria penar muito ainda. [...] Foi aí, quando eu falei, ou eu vou tentar ou eu paro, porque não tem outra (SUELLEN, 2018, p. 5). 
A atleta expressa que, em sua trajetória, a fase de destaque foi a mudança de classificação, entendendo esta como uma conquista pessoal, materializando a possibilidade de jogar no voleibol sentado em competições. Já ao se tratar de um destaque no âmbito coletivo, Suellen ainda destaca a conquista da medalha de bronzes dos Jogos Paralímpicos de 2016:

O que eu destaco no meu percurso é a minha mudança na classificação. Mas isso foi pessoal. A medalha foi no grupo, no coletivo. Foi maravilhoso. Mas, a minha mudança de classificação, poder jogar [...]. Eu joguei o primeiro em 2005, começo de 2006, e agora, como titular, como titular absoluta. Mudança de classificação e tudo. Então, foi emocionante, a hora que ele falou na sala de classificação, eu já comecei a chorar. Mesmo sabendo que tudo ia acontecer, mesmo sabendo, foi pessoal (SUELLEN, 2018, p.16).

Suellen ressaltou que o treinador Ronaldo foi importante nesse processo, pois depois dessa viagem, em 2010, as atletas vislumbravam participar dos Jogos Paralímpicos de 2012 e que, para isso, elas deveriam ficar bem colocadas nos Jogos Parapan-Americanos em 2011. Contudo, para ocorrer uma competição como os Jogos Parapan-Americanos deve haver, no mínimo, quatro países com equipes inscritas. Na época, os países da América Latina e América do Norte que possuíam seleções femininas desta modalidade eram o Brasil, o Canadá e os Estados Unidos. De tal maneira, Suellen explica os desdobramentos do caso:

\begin{abstract}
A gente foi pra Colômbia, treinou uma semana lá com eles, parece que foi uma semana ou um pouco a menos, ajudando, falando das regras, tentando dissipar, aí eles formaram um time e vieram pra cá. Aí se caracterizou como campeonato oficial e ficamos em segundo, perdemos pros Estados Unidos. Esse campeonato eu também não pude jogar porque eu fui convocada e antes da abertura eu fui cortada, porque a gente estava fazendo o negócio de revezamento (por conta da mínima deficiência que cada equipe pode convocar apenas duas atletas) (SUELLEN, 2018, p. 5).
\end{abstract}

Conforme os relatos da atleta Suellen, a seleção brasileira de voleibol sentado se deslocou até a Colômbia a fim de compor uma equipe feminina de voleibol sentado colombiana, visando ter quatro países inscritos na modalidade nos Jogos Parapan-Americanos de 2011, materializando a disputa nesta competição e a possibilidade de competirem nos Jogos Paralímpicos de 2012, conforme sucedeu posteriormente.

Suellen diz que passou o ano de 2011 treinando e intercalando com outra atleta da equipe com mínima deficiência. Narra que "era feito scoult das duas o tempo todo, pra saber quem é que ia, então foi pressão até o fim, até o último momento" (SUELLEN, 2018, p. 5). Depois disso, quando saiu a escalação que iria para os Jogos Paralímpicos de Londres em 2012, a atleta viu seu nome indicado para representar o Brasil na seleção brasileira feminina de voleibol sentado. 
Sublinhamos que as atletas, ao serem questionadas sobre seus percursos com o voleibol sentado, relataram que a prática esportiva paralímpica foi importante por questões de conhecer outras pessoas com deficiência, novos lugares e, principalmente, registrarem suas conquistas e campeonatos, nos quais tiveram a oportunidade de participar a partir das convocações na seleção brasileira. Abaixo, encontram-se fotos que representam as conquistas das atletas - a medalha de prata na competição do Pré-Mundial em 2017 e a delegação brasileira feminina de voleibol sentado com a medalha de prata conquistada nos Jogos Paralímpicos em 2016.

Gizele relembra os Jogos Parapan-Americanos do ano de 2011 que, por conta da colocação obtida, conquistaram vaga para ir aos Jogos Paralímpicos em Londres, na Inglaterra, no ano seguinte, em 2012. Abaixo segue sua expressão sobre esse momento:

Foi 2011 e foi em Moji das Cruzes. Quando todo mundo foi a Guadalajara, os Jogos Pan-Americanos foram em Guadalajara, o vôlei feminino, somente o vôlei feminino sentado foi em Moji. Minha cidade. Nossa estou em casa, com a seleção brasileira na minha casa. Nossa senhora!! E conseguimos a vaga pra Londres em Moji. Oh, me dá até um frio aqui. (Risos) Que boba que eu sou, né. É que eu sou orgulhosa do que eu faço (GIZELE, 2018, p. 5).

Já a atleta Paula, ao ser questionada sobre as competições que foram mais marcantes em relação a sua trajetória, responde: “todas foram importantes, para chegar aonde chegamos com a medalha de bronze, que para muitos é só uma medalha de bronze, não sabem a pressão que temos com nós mesmas" (PAULA, 2018, p. 2). Em sua resposta, consideramos que mesmo que ela entenda que todas as competições foram importantes, o fato de ter conquistado o bronze em Jogos Paralímpicos ganha destaque. Após essa fala, antes de continuarmos a entrevista, Paula finaliza dizendo: "mais marcante foram duas, que foi a minha primeira Paralimpíada de Londres em 2012, e a Paralimpíada do Rio 2016, essas foram inesquecíveis” (PAULA, 2018, p. 2).

As atletas discorrem aspectos sobre os clubes nos quais treinam, mas focaram, principalmente, em expor relatos sobre os percursos na seleção brasileira. Portanto, somando seus depoimentos às informações que encontramos em quadros de medalhas nos sites do Comitê Paralímpico Brasileiro e no site da Confederação Brasileira de Voleibol para Deficientes, apresentamos a compilação dos dados trazidos pelas atletas sobre as competições, nas quais elas participaram, a saber: Jogos Parapan-Americanos; Jogos Paralímpicos; Campeonato Mundial de Voleibol Sentado; e Campeonato Pré-Mundial. Estes eventos esportivos ocorreram no período de 2011 a 2017, em diferentes países. 
Evidenciamos que os percursos esportivos das cinco atletas investigadas incluem a rápida ascensão na carreira, dada a transição da iniciação esportiva para o ingresso na seleção brasileira de voleibol sentado. Tais indícios denotam o amplo potencial de desempenho destas mulheres na modalidade. Para além disso, também é possível que seus percursos tenham sido influenciados pela carente difusão da modalidade entre mulheres com deficiência física no Brasil na época em que ocorreram as suas inserções no esporte paralímpico. Vale referir que tal cenário parece não ter conquistado grandes modificações na atualidade.

Além da rápida ascensão supramencionada, foi possível observar que os percursos esportivos das atletas da seleção são marcados por dificuldades como a dedicação simultânea ao trabalho e ao esporte, as classificações e reclassificações funcionais, a pressão psicológica pelo alcance de altos índices de desempenho em competições para permanecer na seleção brasileira e para ser escalada para as competições, o pequeno reconhecimento familiar e social de ser atleta paralímpica, dentre outros aspectos que foram apresentados. Apesar disso, as entrevistadas construíram representações acerca de seus percursos esportivos, significando-os, especialmente, a partir das ocasiões das competições esportivas, onde estabelecem intercâmbios culturais e se reconhecem como atletas do esporte paralímpico e, sobretudo, como representantes de seu país. Indícios sobre isto foram situados, principalmente, na participação das atletas nos Jogos Paralímpicos.

\section{Considerações finais}

Este estudo objetivou delinear os percursos de atletas da seleção brasileira feminina de voleibol sentado que participaram de Jogos Paralímpicos nas edições de 2012, em Londres, e de 2016, no Rio de Janeiro. Por meio das fontes orais coletadas, constatamos que as memórias acerca dos percursos esportivos das atletas estavam, na maioria das vezes, voltadas aos Megaeventos esportivos destinados às pessoas com deficiência, como os Jogos Paralímpicos e os Jogos Parapan-Americanos, nos quais tiveram destaque na vida pessoal e profissional das jogadoras.

Em suas narrativas, as atletas destacaram que o esporte paralímpico contribuiu para a reabilitação (no caso das atletas com deficiência adquirida), para as questões de lazer e/ou de socialização e para a saúde. Ao memorar suas histórias nas aulas de Educação Física escolar, as atletas que tiveram a vivência e experiência com o voleibol na escola ressaltaram em seus discursos a relevância desse conhecimento, enquanto as que não tiveram essa aproximação com a modalidade convencional, discorrem sobre a dificuldade na fase de transição para o 
voleibol sentado. A partir das narrativas das atletas foi possível identificar que as pessoas sem deficiência que possuem conhecimentos sobre os esportes adaptados e os paralímpicos contribuem para que as pessoas com deficiência se aproximem desse movimento.

O movimento paralímpico tem se alastrado e está crescendo em questões de visibilidade, quando relacionados ao passado. Percebemos que ainda há muito a ser difundido, mas que a relevância desta temática é indiscutível. Conduzir essa investigação com as lentes da História Cultural permitiu que interpretássemos os benefícios da prática esportiva e os cenários que abarcam as experiências das atletas da seleção brasileira de voleibol sentado, compreendendo como foi para essas cinco atletas seus percursos esportivos e suas memórias ligadas as competições esportivas.

Consideramos que este estudo possa ser realizado com a comissão técnica bem como com outras atletas da seleção brasileira feminina de voleibol sentado, o que traria mais informações para a discussão. Para trabalhos futuros, destacamos a possibilidade de interpretar testemunhos de outros personagens que se envolvem com a prática do voleibol sentado de alto rendimento, como treinadores, gestores e atletas, compreendendo a importância de valorizar as experiências e preservar a memória paralímpica brasileira.

\section{Referências bibliográficas}

BARROS, José Costa D'Assunção. A Nova História Cultural: considerações sobre o seu universo conceitual e seus diálogos com outros campos históricos. Cadernos de História, Belo Horizonte, v. 12, n. 16, p. 38-63, 2011.

. Fontes Históricas: revisitando alguns aspectos primordiais para a pesquisa Histórica. Mouseion, Canoas, n. 12, p. 129-159, ago. 2012.

BATISTA, Jani Freitas. Entrevista. [2018]. Entrevistadora: Vitória Crivellaro Sanchotene. Goiânia, 20 de out de 2018. 52min03seg. Entrevista concedida para elaboração de dissertação de mestrado da entrevistadora.

BONI, Valdete; QUARESMA, Sílvia Jurema. Aprendendo a entrevistar: como fazer entrevistas em Ciências Sociais. Revista Eletrônica dos Pós-graduandos em Sociologia Política da UFSC, Florianópolis, v. 2, n. 1, p. 68-80, jan. 2005.

BRASIL. Decreto Legislativo $n^{\circ}$ 186, de 09 de julho de 2008. Convenção sobre os Direitos das Pessoas com Deficiência. $4^{\mathrm{a}}$ Ed., rev. e atual. Brasília, Secretaria de Direitos Humanos, p. 100, 2011.

BURKE, Peter. O que é história cultural? Rio de Janeiro: Jorge Zahar, 2005.

CARDOSO, Vinícius Denardin. O desenvolvimento da carreira esportiva de atletas paraolímpicos no Brasil. Tese (Doutorado em Ciências do Movimento Humano) - Universidade Federal do Rio Grande do Sul. Porto Alegre, 2016.

CARVALHO, Camila Lopes; GORLA, José Irineu; ARAÚJO, Paulo Ferreira de. Voleibol Sentado: do conhecimento à iniciação da prática. Conexões: Revista da Faculdade de Educação Física da Unicamp, Campinas, v. 11, n. 2, p. 97-126, abr./jun. 2013.

CHARTIER, Roger. A história cultural entre práticas e representações. Lisboa: Difusão Editora, 1988. $244 \mathrm{p}$.

DANTAS, José Agtônio Guedes. Ciclo de debates em estudos Olímpicos e Paraolímpicos. Os desafios do voleibol sentado feminino para os Jogos do Rio 2016. In: OLIVEIRA, Ailton Fernando Santana de; 
HAIACHI, Marcelo de Castro. Diferentes olhares dos Jogos Rio 2016: a mídia, os profissionais e os espectadores. Aracaju: Diário Oficial do Estado de Sergipe, 2018, p. 1-378.

DIAS, Gizele Maria da Costa. Entrevista. [2018]. Entrevistadora: Vitória Crivellaro Sanchotene. São Paulo, 30 de out de 2018. 59min36seg. Entrevista concedida para elaboração de dissertação de mestrado da entrevistadora.

FERREIRA, Marieta de Moraes. História, tempo presente e história oral. Revista Topoi, Rio de Janeiro, v. 3, n. 5, p. 314-332, dez. 2002.

FLICK, Uwe. Introdução à pesquisa qualitativa. 3. ed. Porto Alegre: Artmed, 2009.

HAIACHI, Marcelo de Castro. O curso de vida do atleta com deficiência: a deficiência e o esporte como eventos marcantes. Tese (Doutorado em Ciências do Movimento Humano) - Universidade Federal do Rio Grande do Sul. Porto Alegre, 2017.

HERTS, Paula Angeloti. Entrevista. [2018]. Entrevistadora: Vitória Crivellaro Sanchotene. Goiânia, 20 de out de 2018. 33min18seg. Entrevista concedida para elaboração de dissertação de mestrado da entrevistadora.

LE GOFF, Jacques. História e memória. Campinas: São Paulo: UNICAMP, 1990.

LIMA, Suellen Cristina Dellangelica. Entrevista. [2018]. Entrevistadora: Vitória Crivellaro Sanchotene. Goiânia, 20 de out de 2018. 55min58seg. Entrevista concedida para elaboração de dissertação de mestrado da entrevistadora.

LOPEZ, Immaculada. Memória social: uma metodologia que conta histórias de vida e o desenvolvimento local. São Paulo: Museu da Pessoa; Senac São Paulo, 2008.

MUÑOZ GALÍNDEZ, Efraín; MONTES MORA, Sandra. Voleibol sentado: un deporte que da sentido a la vida. Educación Física y Ciencia, La Plata, v. 19, n. 1, 2017.

PESAVENTO, Sandra Jatahy. História \& História Cultural. 2. ed. Belo Horizonte: Autêntica, 2004.

PESAVENTO, Sandra Jatahy et al. História Cultural: experiências de pesquisa. Porto Alegre: Editora da UFRGS, 2003.

REIS, Rafael Estevam; MEZZADRI, Fernando Marinho; SILVA, Marcelo Moraes. As políticas públicas para o esporte paralímpico no Brasil: apontamentos gerais. Revista Corpoconsciência, Cuiabá. v. 21, n. 1, p. 58-69, jan. 2017.

SANCHOTENE, Vitória Crivellaro. Percursos e memórias esportivas das atletas da seleção brasileira feminina de voleibol sentado. Dissertação (Mestrado em Ciências do Movimento Humano) Universidade Federal do Rio Grande do Sul. Porto Alegre, 2019.

; HAIACHI, Marcelo de Castro; MAZO, Janice Zarpellon. Voleibol sentado feminino: em busca de achados sobre as mulheres atletas. Revista Brasileira de Medicina do Esporte, São Paulo, v. 24, n. 6, nov./dez. 2018.

; MAZO, Janice Zarpellon. Voleibol sentado: análise da produção científica brasileira. Revista Thema, Pelotas, v. 15, n. 2, p. 563-574, maio 2018.

SILVA, Ádria Jesus da. Entrevista. [2018]. Entrevistadora: Vitória Crivellaro Sanchotene. Goiânia, 20 de out de 2018. 1h03min25seg. Entrevista concedida para elaboração de dissertação de mestrado da entrevistadora.

STAKE, Robert. Pesquisa Qualitativa: estudando como as coisas funcionam. Porto Alegre: Penso, 2011. 263 p.

VAMPLEW, Wray. The history of sport in the international scenery: an overview. Revista Tempo, Niterói, v. 17, n. 34, p. 5-17, 2013.

VIANA, Márcia Rafaella Graciliano dos Santos; CHAVES, Lucas Tavares dos Santos; PEREIRA, Thalles Albert Jarsen de Melo Santos. Pessoas com deficiência física e os benefícios da prática do vôlei sentado. In: ENCONTRO ALAGOANA DE EDUCAÇÃO FÍSICA INCLUSIVA, 6, 2015, Alagoas. [Anais...], 2015. p. 1 - 4. 